\title{
Blast protection in military land vehicle programmes: approach, methodology and testing
}

\author{
M. Müller, U. Dierkes \& J. Hampel \\ IABG Lichtenau, Dept. VG23 - Land Systems, Germany
}

\begin{abstract}
Personnel safety is crucial in operations where mines pose a threat. In peacekeeping and peace-enforcing operations' occupant protection is given top priority. During the past decade up to now, the IABG Defence \& Security Department has been supporting the German $\mathrm{MoD}$ and Industry in most national and international vehicular mine protection and IED-protection programmes with independent engineering consultancy services and basic research. The original work shifted from the focus on protection against blast mines to a combined protection against blast and projectiles. With regards to the field of terrorist (IED) attack protection, the insights in blast mine protection still remain the basic background at which protection measures can be illustrated. This paper gives a brief overview about the blast mine protection field. Starting with general structural effects caused by a blast detonation, special focus is placed on the occupant loading and how it can be reduced. A brief description of simulation methods and injury criteria which are in focus for vertical loading conditions is therefore given. Beside vehicular qualification trials basic research on occupant protection by means of test rig configurations is presented. The test rigs for occupant safety systems TROSS I \& TROSS II $^{\circledR}$ give the opportunity to investigate different loading conditions and interior measures in a reproducible way. As an outlook aspects of the growing R\&D topic "Research of protection against roadside bombing (IED)" are discussed.

Keywords: mine protection, blast loading, structural dynamics, occupant dynamics, dummy measurement.
\end{abstract}




\section{Introduction}

In out-of-area and peacekeeping missions mobility of armoured vehicles beside the cleared and swapped tracks is essential. In those situations the ground forces are endangered by different land mine types.

Since 1997 research institutes, universities and engineering companies in Germany combined their expertise on protection of armoured vehicles in a working group. This group defined basic research programmes on blast and EFP protection and supports the $\mathrm{MoD}$ in transferring the resulting know-how in protection programmes of armoured land vehicles of the German Bundeswehr (Figure 1).

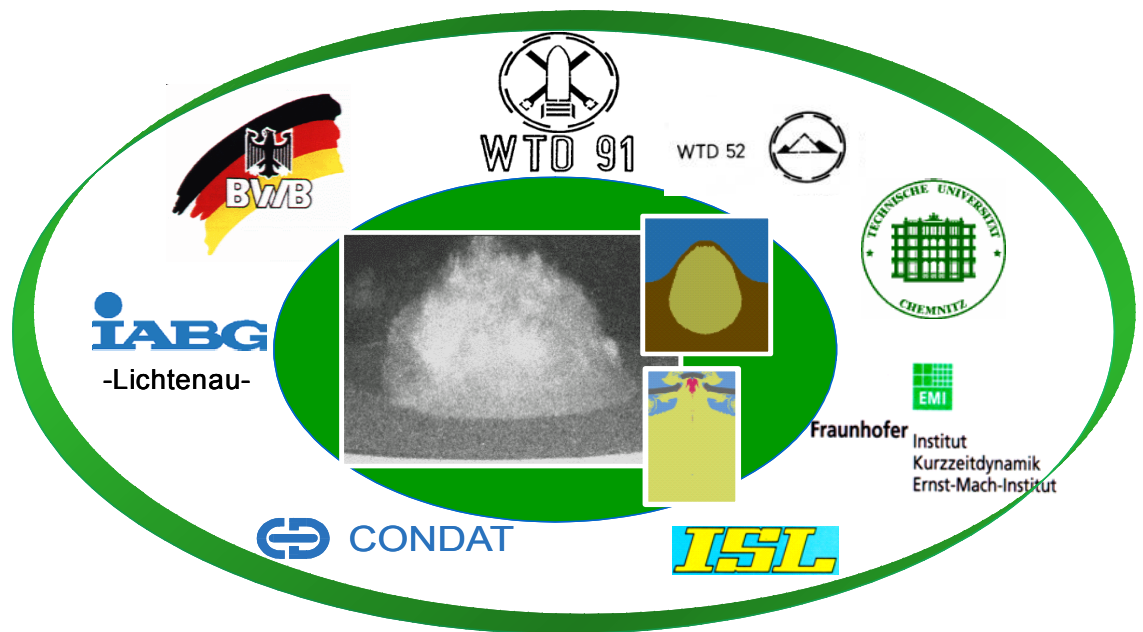

Figure 1: $\quad$ Working group on Landmine and IED protection.

The development processes of protection for armoured land vehicle systems started with reference data for Mine effectiveness vs. Mine Protection effectiveness gained throughout basic plate trials. Real mines are classified by the amount of explosive contained in terms of equivalent TNT charge. For landmines filled with other explosives than TNT, the explosive charge is converted with available factors into TNT equivalent.

There are several parameters which affect the blast wave effects onto a vehicle structure:

The shape of the charge, the casing, the burial depth, the type of soil and in any case the standoff from the vehicle bottom (ground clearance) and the bottom plate mass.

An armoured vehicle basically is threatened by two different physical principles: by the explosive blast pressure and by kinetic energy projectiles (masses, fragments). Pressure mines are initiated under track and wheel, but there are also landmines with magnetic or tip wire detonators which initiate the 
charge below the belly. A mine protection solution has therefore not only to harden the attacked zone (bottom section) but also to design the complete compartment in a safe way. To handle the local mine effect the belly structure has to remain intact. This is a necessary first condition but local and global stresses migrate through the vehicle even if the blast can be kept outside.

High structural stresses will lead to local material collapse at fixation zones and interior devices and equipment can become a "secondary" projectile. Mine protection is a consideration of vehicle floor, crew cabin and occupant response.

Local deformations with velocities up to $200 \mathrm{~m} / \mathrm{s}$ are a vital threat if they come in direct or indirect (for example via a seat structure) contact with the occupant. To meet these objectives the whole vehicle structure has to be analyzed to minimize local and global mine effects and therefore ensure the survivability of the vehicle crew.

An essential aspect in the development process of a mine protection solution is the numerical simulation.

The number of detonation trials in the development process is limited. Especially trials with dummy measurements are done only at milestone and qualification steps in the programme

A key aspect in the development of a mine protection system is therefore a combination of structural- and occupant simulation.

The calculation of the structural response under blast load starts with the pressure distribution under the bottom section in a eulerian code. This blast model takes into account the type of explosive, the shape of the charge and soil conditions. It can be precalculated for different standoffs and then be mapped onto different structural FE-Models. The structural response at important zones of the vehicle model calculated via explicit codes (AUTODYN, LS-DYNA) can then be used as input for multibody occupant models (MADYMO).

Plate and segment tests which measure dynamic and plastic deformation and moreover accelerations at important structural zones have been used to calibrate material- and damage models.

A full spectrum of mine protection for a vehicle also takes overmatch situations into account. Numerical overmatch simulations show additional resources against higher threats than the system was designed for.

\section{Aspects of structural dynamics}

In mine protection the structural integrity of the bottom section respectively the crack resistance of the protection module is the minimum requirement. For an effective occupant protection in addition more boundary conditions have to be met. A direct contact of the occupant with highly stressed structural zones has to be avoided as those high shock accelerations cause severe traumatomechanic injuries.

All structural parts which are likely to come in contact to the occupants have to maintain within a tolerable acceleration level throughout the main stress phase. 
A criterion of crucial importance is the dynamic bending directly above the detonation spot. If the local buckle with its high velocity which typically reaches up to $160 \mathrm{~m} / \mathrm{s}$ within $1-2 \mathrm{~ms}$ comes in direct contact with interior structures the velocities will be transported to other components. This deformation is a parameter to be minimized during protection optimization. In case of a secondary contact the velocity of the dynamic bulge is a key parameter for the transport of structural stress transport. So if contact can't be avoided it has to be shifted to a "late" time point when the velocity already dropped into lower severity.

For the assessment of structural protection measures acceleration sensor data recordings are taken in each trial of a protection programme. They are measured with special high shock accelerometers. For an assessment of failure probabilities shock response spectra are plotted and frequency contents with high velocities and deformations are identified.

A measurement of structural accelerations directly above the detonation zone is hardly possible due to the damage high shocks above $100000 \mathrm{~g}$ cause even in damped sensors.

Instead of sensor data a high speed video of the dynamic bulge with a sufficient sampling rate ( $>10000$ frames per second) allows the generation of dynamic motion data of marked tracers on even highest stressed zones in the video over a time duration of 1 to $20 \mathrm{~ms}$. By means of pixel analysis of this highspeed video the dynamic bending of an arbitrary point visible during the deformation phase is calculated. A comparison of dynamic bending behaviour of different protection structures and an interpretation in categories of follow up damage potential is therefore possible. Figures 2 and 3 show typical measurements during a mine detonation under a belly of a protected vehicle.
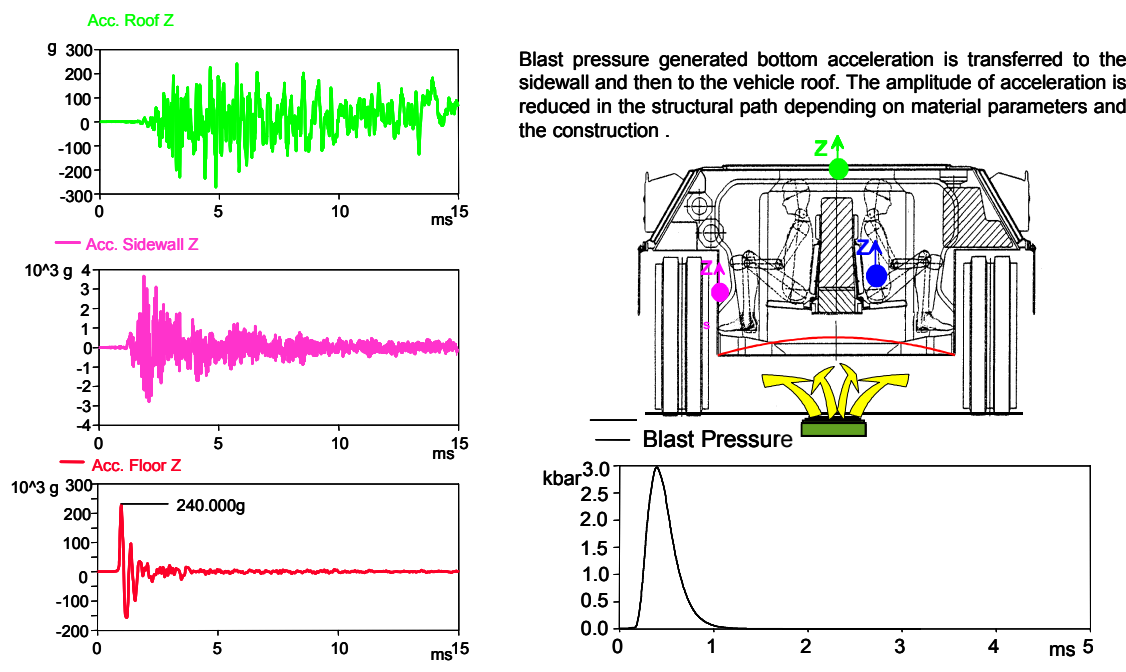

Figure 2: $\quad$ Structural acceleration during a mine detonation under a vehicle belly. 


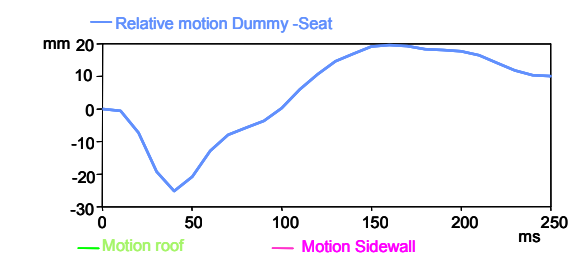

Due to the roof mounting of the seats the bottom deformation isn't directly transferred to the occupants. Relative to the seat the occupant is pushed into the cushion while the seat moves upward. This is followed by a rebound of the seat and the dummy is held back in the restraint system.

In general the roof deformation starts about 6-8 ms after onset of the sidewall deformation. Depending on the structure elastic roof movement can be greater than sidewall

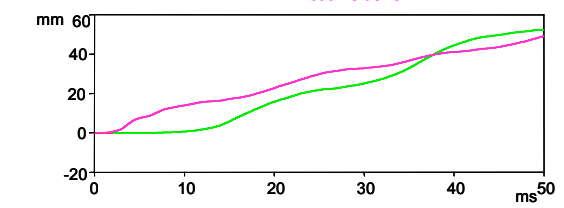
or floor movement.
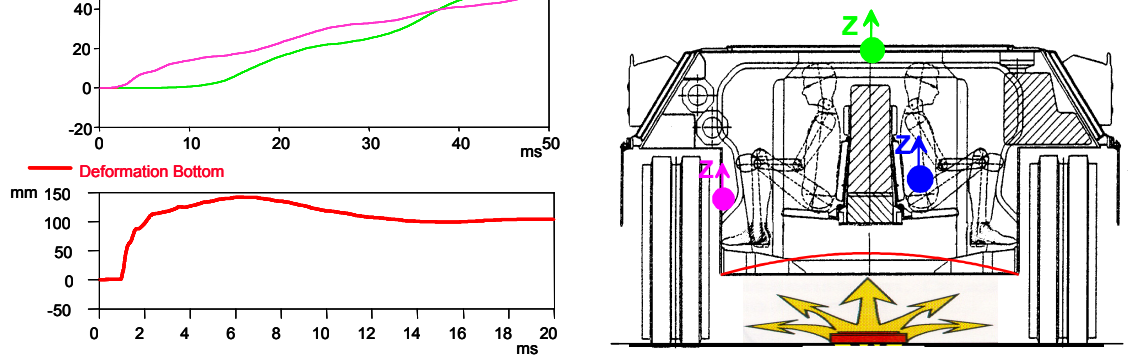

Figure 3: Structural deformation during a mine detonation under a vehicle belly.

Detonating the charge in a steel pit allows competitive testing without soil influence in a reproducible way, as described in STANAG 4569 (AEP-55 Volume 2). The configuration of steel-pit and charge is designed in such a way that the same local effects, i.e. bottom plate deformation and deformation velocity of a steel plate above the charge, were reached as for the situation of a reference mine surrogate buried into sand.

In early development phases plate trials on a test rig optimise the design of the protection module. Not only static values like plastic deformation but also the transient dynamics of a plate are taken into account.

\section{Aspects of occupant dynamics}

During a mine detonation underneath an armoured vehicle different effects lead to critical stresses onto the occupants.

Primary effects like air pressure and splinters through bottom rupture have to be prevented by the actual mine protection module. In addition the blast wave causes deformation in the bottom plate and shock migration through the connection elements and components which stand in direct contact to the occupant.

\subsection{Dummy measurements}

The development of protection measures is directed to reduce biomechanical loads during the detonation and rebound phase in a way that injury criteria limits are met. The measurement tool of choice is the Hybrid III 50\% dummy-manikin. Although designed for frontal impact it's completeness of sensor locations at 
legs, pelvis, neck and head and its seating posture and biofidelity design made it fit for trials with different seat and restraint systems.

The dummy typically movement is filmed with 1000 to 2000 frames per second. The kinematic motion analysis allows in combination with the accelerometer values a balanced assessment of occurring stress levels. Remarkable events like collisions of femur or head with interior parts or even the roof construction can be identified.

In all German mine qualification programmes the HIII was the standard measurement tool for the acquisition of stress levels at certain locations combined with injury criteria. In IED side facing impact situations the Euro SID dummies have proven to give good results since the starting point on injury criteria are based on ECE Norms and the Euro NCAP references. Experimental research and vehicular qualification trials with the HIII showed that certain body regions are most critical regarding acceleration based injuries:

In case of a mine detonation below the passenger compartment the crew is exposed to serious injury levels arising from:

- $\quad$ feet /leg fractures/contusions by intruding bottom and pedal elements (Feet and lower tibia which are most likely placed in endangered areas are loaded by high dynamic intrusions and bending.)

- Lumbar spine compression by high rate acceleration

(A transfer of accelerations into the seat system might lead to critical compressions in pelvis and lumbar spine.)

- Head and neck injuries by blunt impact onto rigid interior or roof parts: (A unrestrained occupant will hit interior parts or walls causing head accelerations and neck flexion and extensions above limit values)

- Injury caused by blunt and sharp impact of broken and loose equipment.

All channels of the dummy and the accelerometers on the structure usually are triggered by a CCD chip sensing the light flash of the ignition or a short circuit wire. The loading duration of a mine blast affected structure happens in a time duration shorter than 2-4 ms. This short impact causes the structure to respond according to its eigenfrequencies. The time duration of the maximal occupant loading usually takes from $15-40 \mathrm{~ms}$. A measurement duration of $250 \mathrm{~ms}$ is in the majority of cases sufficient to make decisions on survivability of the occupants and equipment.

\subsection{Injury criteria}

In injury mechanics two important parameters determine the tolerance limit values of injury criteria $[1,2]$ :

- injury probability and

- injury severity.

In STANAG 4569 mine protection testing guidelines most nations agreed to a tolerable severity level of AIS $2+$ connected with a risk probability of $10 \%$. This 
means in common sense that occupants are capable of leaving the vehicle on their own after a mine detonation.

In NATO/RTO group HFM-090/TG25 the injury criteria were discussed and harmonized for STANAG 4569, AEP 55 Volume 2.

\section{Basic research}

\subsection{Test Rig for Occupant Safety Systems TROSS ${ }^{\circledR}$}

Main focus is the response of structures under blast loading conditions and how to get information about local accelerations acting on the occupant. Interior systems like footrests, pedals and seats transport the acceleration with different transfer properties. Detonation tests within the TROSS experiments analyse stress reduction potential by decoupled designs and optimised restraint systems. As a worst case benchmark rigid steel seats and rigidly fixed footrests are evaluated e.g. against up to date air cushioned truck seats or new designed crashworthy connection elements (Figure 4).

\section{Steelchair Trial:}

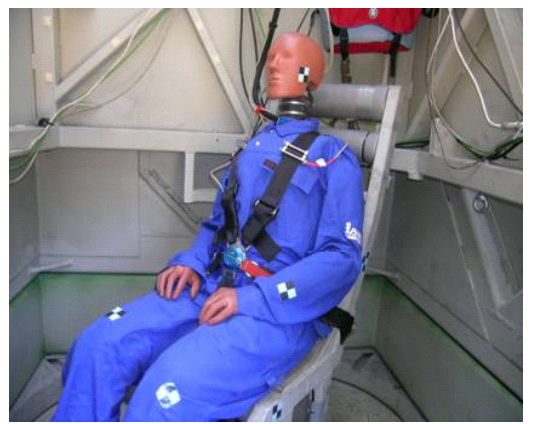

Steelchair MADYMO Simulation:

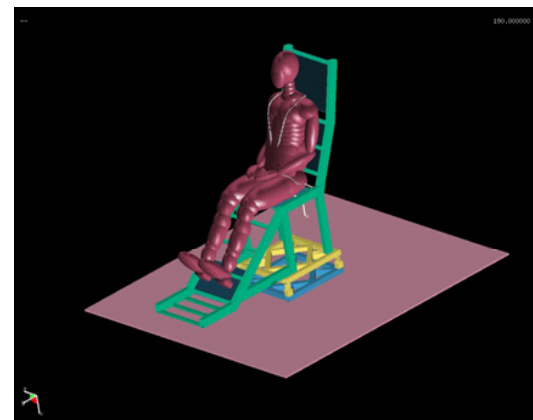

Figure 4: Steel chair dummy test and occupant simulation.

\subsection{TROSS I ${ }^{\circledR}$ test campaign example "interior collision"}

Due to the limited space in military vehicles the problem of head contact with roof structures and femur steering wheel contact was investigated with the TROSS I test rig. In the scaled charge trials typical mine detonation footrest and seat input velocities were reached by scaling down the charge and reducing the standoff. Bottom Plate deformations of up to $100 \mathrm{~mm}$ brought the HIII head in hard contact to a rigid roof plate (Figure 5).

Maximum acceleration in case of head contact could clearly be reduced by a helmet but on the other hand neck loading duration was extended (Figure 6). Wearing a helmet in case of no head contact had hardly any influence on Neck Forces and moments at all. 

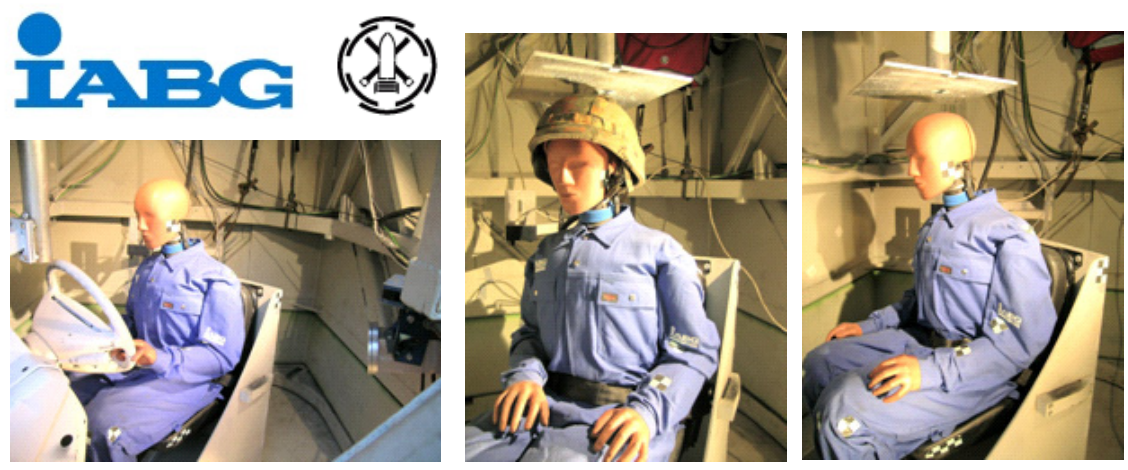

Figure 5: Test configuration for steering wheel / femur and head /roof contact.

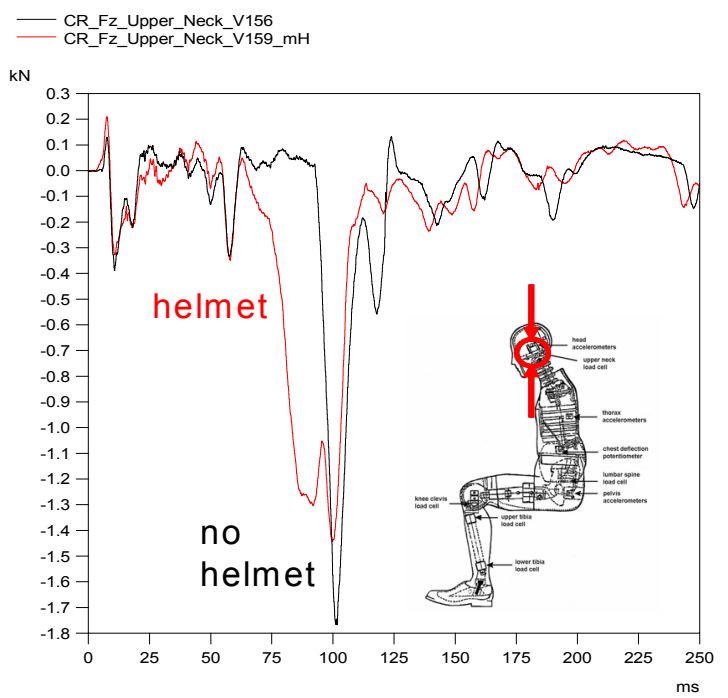

Figure 6: Exemplary neck compression force

\subsection{TROSS II ${ }^{\circledR}$ test campaign example "sand / steel pit comparisons"}

The scaled tests in the TROSS I test rig remained in the elastic plate bending area. To simulate high structural shocks not only in the bottom plate but also in the whole compartment enhanced test rig trials were done. A free moving cabin in the weight class of light armoured vehicles allows testing of all kinds of mission important systems with special focus on occupant stresses transferred by seating and footrest parts (Figure 7). The lower limit for the dummy movement within the cabin showed to be the global movement although local velocities are above this level. 


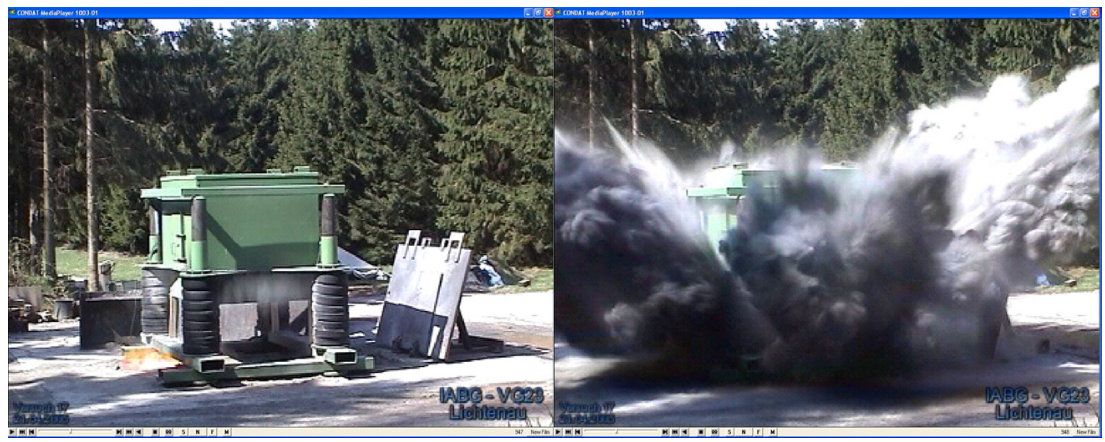

Figure 7: $\quad$ TROSS II Tests in sand.
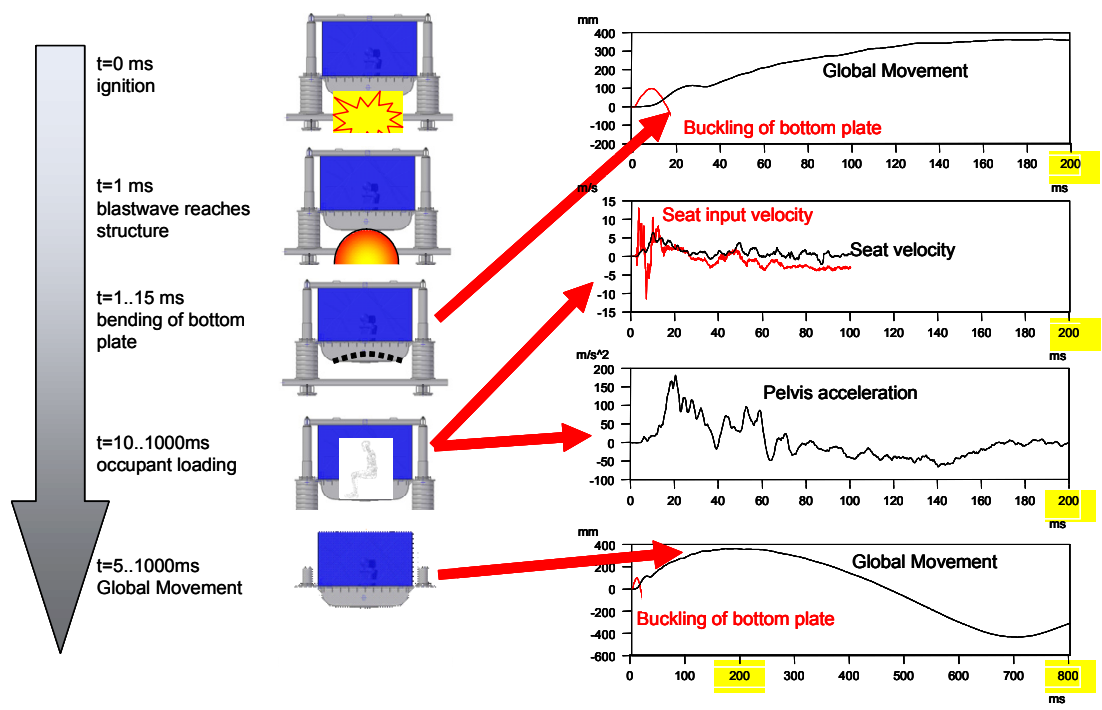

Figure 8: $\quad$ Measurements at TROSS II test rig blown up by a 1:1 charge.

Structural velocities of sidewall or roof reach more than $10 \mathrm{~m} / \mathrm{s}$ within few milliseconds whereas the dummy velocity and the global velocity only reach 6 $\mathrm{m} / \mathrm{s}$ and $4 \mathrm{~m} / \mathrm{s}$ respectively (Figures 8 and 9 ).

\section{Conclusions}

Contact trials showed helmet effects to be ambivalent. Kevlar helmets reduce head space and increase neck force duration. Only in case of sharp edge contact positive acceleration reduction effects outbalanced the negative force increasing influences. 


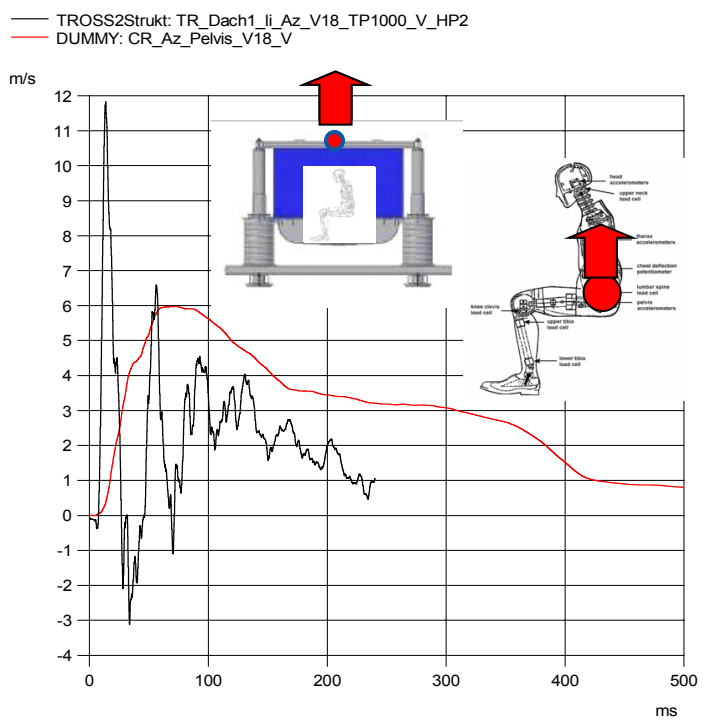

Figure 9: $\quad$ Structural velocity and Dummy pelvis velocity.

Test campaigns with charges out of sand and out of a steel pit showed equal results in short time structural dynamics and occupant loading. Differences in impulse transfer were shown to be not relevant for dynamic bottom bending and velocities. Compared to local maximum cabin deformations the global movement in general was shown to be of minor importance for injury criteria values.

\section{Outlook}

The test rig approach which has been proven successfully in the field of mine protection is now adopted for the terrorist IED threats (Figure 10).

Forming a testing matrix with relevant charges and standoffs and material testing is started by means of dynamic plate and segment tests.

Based on the integrated test rig TRAILER ${ }^{\circledR}$, which allows to study the dynamics and forces in highly stressed structures directly above a detonating mine, IABG has developed a new test environment called IED-TRAILER ${ }^{\circledR}$ for systematic investigations on the effects of large blast IEDs (improvised explosive devices).

In a first experimental series, the dynamic response of different steel plates exposed to high blast load has been examined. The HE charges varied from $2 \mathrm{~kg}$ to $300 \mathrm{~kg}$ TNT at detonation distances between $2 \mathrm{~m}$ and $15 \mathrm{~m}$. Pressure, momentum and time resolved bulging of the plates have been measured. The results provide a basis for the characterization of the severity of different blasting conditions. 
To facilitate test series with large charges, IABG has worked out a method by which the same response of a structure as achieved by a large IED can be generated with a drastically reduced amount of explosive. The method has been validated and its range of application determined. Actually activities are running to extend the IED testing on vehicle segments and complete vehicles.

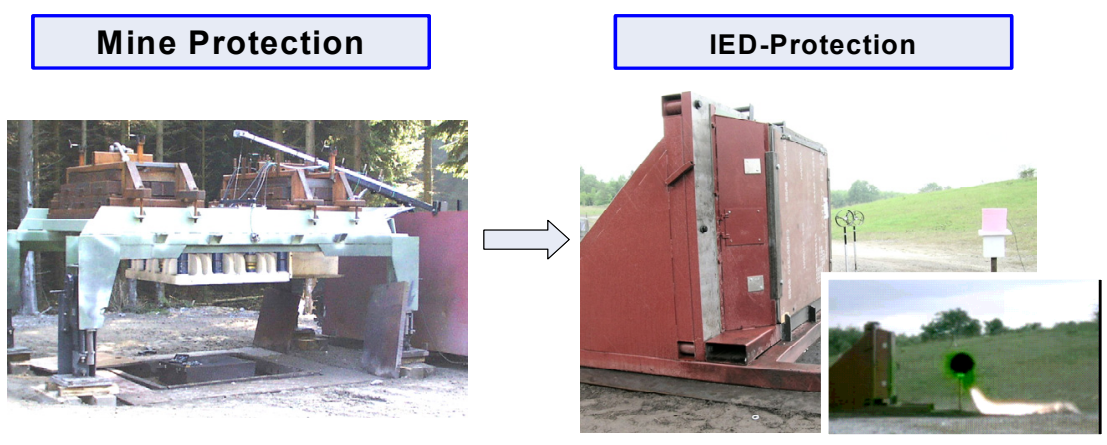

Figure 10: Test Rigs for Mine- and IED protection.

\section{Acknowledgement}

The results presented in the paper are an IABG Lichtenau part of the R\&D Programme of the German working group on mine protection of armoured vehicles coordinated and funded by WTD 91 Dept. 410 Meppen proving ground.

\section{References}

[1] Mertz, H. (1993): Anthropometric Test Devices, Accidental Injury, Biomechanics and prevention. In Accidental Injury: Biomechanics and Prevention. edited by Nahum, A., Melvin, J. Springer-Verlag.

[2] Albert I. King: FUNDAMENTALS OF IMPACT BIOMECHANICS: Part 2-Biomechanics of the Abdomen, Pelvis, and Lower Extremities. 